\section{Orthodoxy and homoeopathy}

SIR-The issue of whether basophils degranulate at infinite concentrations of IgE in a cyclic manner (Nature 333, 816; 1988) is of great scientific and clinical interest. Yet the hardly dispassionate whirl of experiments and 'counter-experiments' (all attempting to convince the reader of an even-handed perspective) strain the thesis that research can live comfortably in separation from its more secular environment of politics and personal opinion.

One might lament the apparent inability of experimentation to resolve the issue. The reader is left, if he has no prior opinion, much like an undecided voter at the polls - amid the confident exhortations of campaigners manning the doors. Perhaps a team of politicians and publicopinion pollsters could be sent to the laboratories involved to help out the undecided.

JAMES A. SCOTT Massachusetts General Hospital, Boston, Massachusetts 02114, USA

SIR-The recent hullabaloo about ignoring negative results in the homoeopathy study may be only the tip of the iceberg. Unfortunately, as many medical scientists are already sceptical about homoeopathy, they will find comfort in this - and will ask what else could be expected. They do so at their peril. Clearly, ignoring negative results may be a disease far more prevalent than has been suspected and may not exist only in laboratories that attempt to investigate homoeopathy. Negative results, important as they are, often find their way into the wastepaper basket. Could this not also indicate a problem with the editorial policies of scientific journals which very rarely publish such results? In view of the suspicion that fraud is generally on the increase in science, such audits (perhaps random and unexpected), might be a good idea in all laboratories, even those doing conventional scientific work. The results of such audits might surprise everyone. Mark A. Gillman South African Brain Research Institute, Suite 9, Highlands House,

173 Louis Botha Avenue,

Orange Grove 2192,

Johannesburg, South Africa

SIR-Those of us who practise homoeopathy and are interested in its scientific investigation can take some small satisfaction at seeing the assertion, made by homoeopaths for many years, that extreme dilutions do have biological effects, enter the realm of scientific discourse. For too long this claim has been derided as beyond the bounds of possibility and unworthy even of consideration.
Thanks to you and the editors of certain other journals, the cat is now out of the bag. It will not be put back by insults or by a priori refusal to believe that such a phenomenon is possible.

Nor yet will the controversy be resolved by your post hoc inquiry which was, by both accounts, hasty. Theatricals such as the taping of foil-wrapped randomization codes to the ceiling can hardly be described as established scientific procedure.

Your delegation included no biological scientists, so this was not peer review, while the very composition of your delegation implies that it had been decided, in advance, that the explanation of the reported results must be sleight-of-hand, or fraud, as you did not include anybody capable of distinguishing genuine results from a technical error made in good faith. One wonders how many biological scientists (or conjurers) would presume to deliver a verdict on five years' work in physics involving collaboration between six independent laboratories, after just five days' investigation at one laboratory.

Neither can extreme dilution effects be prohibited by scientific law. There has been talk of 'violations of fundamental scientific principles'. But the only specific victim proposed has been the law of mass action. If the phenomenon is physically rather than chemically mediated, as proposed by Benveniste's group, then this law is irrelevant. Certainly no fundamental principles, such as the laws of thermodynamics, are at stake.

The question of the action, or lack thereof, of extreme dilutions will not be resolved by polemics, but only by genuine application of the scientific method. Extended and accurate experiments must be carried out, with control, but without prejudice, followed by publication, criticism and repetition.

Royal London Homoeopathic Hospital,

Great Or:nond Street,

London WC1N $3 H R$, UK

SIR-The appearance of a new journal always attracts interest and the publication on 30 June 1988 of the first issue of New Approaches to Truly Unbelievable and Ridiculous Enigmas was no exception. But I wonder how many readers were shaken (not to say stirred) by the subsequent publication of comment which indicates that editorial wisdom in that journal, though still detectable, has become infinitely diluted in an ocean of rhetoric? Perhaps science, like journalism, also has a silly season.

Ham Cottage, Albourne Road,

Hurstpierpoint, West Sussex BN6 9ES, UK

\section{From other letters}

THE Benveniste findings deserve to be investigated in a calm, unpressured and unprejudiced environment, when they will probably vanish like $\mathrm{N}$-rays and polywater. Your rushed and evidently prejudiced attempt to discredit them has probably killed any chance of such a deliberate assessment occurring.

Alexander M. Grimwade 706 Cambridge Road,

Bala Cynwyd, Pennsylvania 19004, USA

BENVENISTE's report does provide some evidence that insufficient effort was made to eliminate systematic and subjective biases in the experiments. But is this sufficient to label the results a "delusion"? I think not. Neither, apparently, did the team, as they have attempted to further "build a case" against Benveniste by throwing in a number of non sequiturs. Why should they have been "dismayed" by who paid the researchers' salaries? So what if the experiment didn't work "all the time"? Show me one that does, and I'll show you one where somebody has been fudging.

\section{University of Ottawa,}

SCOTT FIndLAY

Biology,

30 Somerset $E$.,

Ottawa, Ontario, Canada K1N6N5

WHY should one require any more or less caution, make more or less study design and execution demands on an experiment that does not fit into a current explanatory (and so theoretical) model than one that does? It could be argued that it is when results fit neatly into current scientific dogma that a study should be required to be more stringently executed than if they do not, lest in confidence we make lax assumptions and so overlook perhaps more important alternative explanations for the results. Lateral thinking is a skill scientists could benefit from a bit more of.

The importance of the article by Benveniste and coworkers is not in the results of the study itself but in the fact that it was published in Nature, rather than in the British Homoeopathic Journal. Homoeopathic and other journals have for years published the results of experiments demonstrating the activity of ultrahigh dilutions. Many of these studies have been done in a scientifically rigorous fashion.

Office of the Surgeon General,

WAYNE B. JONAS Health and Fitness Division,

5109 Leesburg Pike,

Falls Church, Virginia 22041-3258, USA

Letters submitted for Correspondence should be typed, double-spaced, on one side of the paper only. 